12 Bond GR, Drake RE, Becker DR, Mueser KT. Effectiveness of psychiatric rehabilitation approaches for employment of people with severe mental illness. J Disab Policy Stud 1999;10:18-52.

13 Wehman P, Revell WG, Kregel J. Supported employment: a decade of rapid growth and impact. In: Weham P, Revell WG, West M, eds. Supported employment research: expanding competitive employment opportunities for Research and Training Center on Supported Employment, 1997:1-18. 14 ERMIS Database. Dorking:European Economic Interest Grouping, 1998.

15 Clark M, Oxman AD. The Cochrane Collaboration reviewers'handbook version 4.0. Oxford: Cochrane Collaboration, 1999.

16 Marshall M, Lockwood L, Bradley C, Adams C, Joy C, Fenton M. Unpublished rating scales-a major source of bias in randomised controlled trials of treatments for schizophrenia. Br J Psychiatry 2000;176:249-52.

17 Beard JH, Pitt RB, Fisher SH, Goertzel V. Evaluating the effectiveness of a psychiatric rehabilitation program. Am J Orthopsychiatry 1963;33:701-12. 18 Dincin J, Witheridge TF. Psychiatric rehabilitation as a deterrent to recidivism. Hosp Community Psychiatry 1982;33:645-50.

19 Griffiths RD. Rehabilitation of chronic psychotic patients. Psychol Med 1974;4:316-25.

20 Okpaku SO, Anderson KH, Sibulkin AE, Butler JS, Bickman L. The effectiveness of a multidisciplinary case management team on the employment of SSDI applicants and beneficiaries. Psychiatr Rehabil J 1997;20:34-41
21 Wolkon GH, Karmen M, Tanaka HT. Evaluation of a social rehabilitation program for recently released psychiatric patients. Community Ment Health J 1971;7:312-22.

22 Chandler D, Meisel J, Hu T, McGowen M, Mintz J, Madison K. Client outcomes in a three year controlled study of an integrated service mode agency. Psychiatr Serv 1996;47:1337-43.

23 Bond GR, Dietzen LL, McGrew JH, Miller LD. Accelerating entry into supported employment for persons with severe psychiatric disabilities. Rehabil Psychol 1995;40:75-94

24 Drake RE, McHugo GJ, Becker DR, Anthony WA, Clark RE. The New Hampshire study of supported employment for people with severe mental illness. J Consult Clin Psychol 1996;64:391-9.

25 Drake RE, McHugo GJ, Bebout DR, Harris M, Bond GR, Quimby EA. A randomized controlled trial of supported employment for inner-city patients with severe mental illness. Arch Gen Psychiatry 1999;56:627-33.

26 Gervey R, Bedell JR. Supported employment in vocational rehabilitation. In: Bedell JR, ed. Psychological assessment and treatment of persons with severe mental disorders. Washington, DC: Taylor and Francis, 1994.

27 McFarlane WR, Dushay RA, Deakins SM, Stasny P, Lukens EP, Toran J, et al. Employment outcomes in family-aided assertive community treatment. Am J Orthopsychiatry 2000;70:203-14

(Accepted 20 October 2000)

\title{
Who retires early from the NHS because of ill health and what does it cost? A national cross sectional study
}

\author{
Shriti Pattani, Nick Constantinovici, Siân Williams
}

Occupational Health and Safety Unit, Royal Free Hampstead NHS Trust, London NW3 2QG

Shriti Pattani specialist registrar Siân Williams consultant

Department of Primary Care and Population

Sciences, Royal Free and University College Medical School of the University of London, London NW3 2PF

Nick

Constantinovici clinical lecturer

Correspondence to: Siân Williams

Sian.Williams@ rfh.nthames.nhs.uk

BMJ 2001;322:208-9

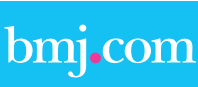

Details of how NHS pensions are

calculated are given on the BMJ's

website. This article is part of the BMJ's trial of open peer review, and documentation relating to this also appears on the website
About one million people are employed by the NHS in England and Wales, 96\% of whom belong to the NHS occupational pension scheme. ${ }^{1}$ The scheme allows early retirement because of ill health for employees "incapable of discharging efficiently the duties of their employment by reasons of permanent ill-health or infirmity of mind or body." There is no requirement for the employer to attempt to offer a more suitable job. This study estimates the magnitude of the problem in terms of annual rates of retirement because of ill health, the direct cost to the NHS Pensions Agency, and whether this ill health is caused by work.

\section{Participants, method, and results}

We examined retirement forms for the first 2000 of 5469 applicants from England and Wales who were granted retirement during 1998-9 because of ill health. ${ }^{1}$ Complete data were obtained on 1994 of

them. Their mean age was 51.6 years (SD 7.4 years) and $72 \%$ were female. The commonest reasons for retirement because of ill health were musculoskeletal (49\%), psychiatric (20\%), and cardiovascular conditions $(11 \%)$. The table shows inverse linear trends $(\mathrm{P}<0.001)$ in the frequency of musculoskeletal and psychiatric diagnoses across occupational groups, musculoskeletal disorders being relatively more common in jobs likely to have a higher manual element (table).

We asked our sample about their length of NHS service and whether they believed their ill health was caused by work. Their views were compared with the answers given by their managers to a similar question on the form for retirement from ill health. Of the 1317 retired workers who replied, $87 \%$ had worked in the NHS for at least 10 years (mean 21.2 (9.1) years). Almost half of those who retired because of musculoskeletal or psychiatric conditions ( $43 \%$ in both cases) thought their ill health was caused through

Type of medical condition and rates of retirement because of ill health for 1998-9 in England and Wales, by occupation. Values are numbers (percentages) unless stated otherwise

Reason for retiring because of ill health (study sample)

Total NHS employees

\begin{tabular}{lccccccc}
\cline { 2 - 5 } Occupational group & Musculoskeletal & Psychiatric & Cardiovascular & Other & Total & $\begin{array}{c}\text { Retired } \\
\text { workers* }^{*}\end{array}$ & $\begin{array}{c}\text { Retirement rate† } \\
\text { (per 1000) }\end{array}$ \\
\hline Ambulance workers & $65(68)$ & $12(13)$ & $6(6)$ & $12(13)$ & $95(5)$ & 261 & 15.1 \\
\hline Healthcare assistants or support & $339(57)$ & $61(10)$ & $77(13)$ & $117(20)$ & $594(30)$ & 1631 & 13.0 \\
\hline Nurses or midwives & $364(50)$ & $144(20)$ & $70(9)$ & $153(21)$ & $731(36)$ & 2005 & 4.5 \\
\hline Technical or professional staff & $42(45)$ & $25(27)$ & $4(4)$ & $23(24)$ & $94(5)$ & 257 & 2.0 \\
\hline Administration or estates staff & $118(38)$ & $94(30)$ & $31(10)$ & $66(22)$ & $309(15)$ & 847 & 4.0 \\
\hline Doctors or surgeons & $33(27)$ & $40(33)$ & $20(17)$ & $28(23)$ & $121(6)$ & 331 & 4.9 \\
\hline Other & $22(44)$ & $13(26)$ & $7(14)$ & $8(16)$ & $50(3)$ & 137 & NAł \\
\hline Total & $983(49)$ & $389(20)$ & $215(11)$ & $407(20)$ & $1994(100)$ & 5469 & 5.5 \\
\hline
\end{tabular}

${ }^{*}$ Obtained by applying the percentage distribution of occupational groups from our sample to the total number of retired workers (5469) reported for 1998-9.' tObtained by dividing the number of people retired from each occupational group by the corresponding NHS workforce as at September $1997^{2-4}$ : ambulance workers, 17 246; healthcare assistants/support staff, 125 101; nurses/midwives, 448 518; technical/professional staff, 128 698; administration/estates staff, 209 616; doctors/surgeons, 67192.

‡Denominators not available. 
work. This belief was shared by their managers in $24 \%$ of cases of retirement on musculoskeletal grounds (57\% agreement), but in only $4 \%$ of retirements for psychiatric reasons ( $8 \%$ agreement).

The 1998-9 rate of retirement because of ill health in England and Wales was 5.5 per 1000 NHS employees. The table shows a wide variation across occupational groups. Ambulance workers were seven times more likely to retire on grounds of ill health than technical or professional staff. ${ }^{2-4}$ We estimate that the cohort of 5469 NHS employees who retired early in 1998-9 will cost the Pensions Agency an additional $£ 416 \mathrm{~m}$ more up to age 70 than would have been expected if they had retired normally (see $B M J$ website). Two thirds of the total sum will be received by nurses $(£ 180 \mathrm{~m})$ and doctors $(£ 104 \mathrm{~m})$.

\section{Comment}

Rates of early retirement were higher in jobs likely to involve more manual work (mostly because of musculoskeletal problems). This may reflect a higher incidence of work related injuries in these jobs. Alternatively, musculoskeletal conditions leading to incapacity may preclude return to manual work. The greater acceptance by managers that work was responsible for musculoskeletal disabilities may reflect specific, witnessed musculoskeletal injuries at work. The work related component of psychiatric illness may be less tangible and thus less apparent to managers.

This is the first major study of retirement because of ill health in the NHS. Our rate of retirement because of ill health of 5.5/1000 NHS employees compares with rates of $2 / 1000$ to $25 / 1000$ employees reported in a recent study of six UK industries (four public and two private) ${ }^{5}$
The huge cost to the NHS Pensions Agency of retirement because of ill health could be reduced if the NHS were able to prevent some work related ill health and to encourage redeployment where ill health prevents staff from continuing in their normal job. There is a need for high quality research to identify effective interventions in these areas. This is particularly pertinent in the current employment climate and could help the NHS retain experienced staff at a time of crisis in recruitment and retention. We will contact our cohort again to find out whether they have found alternative work and, if so, to identify predictors of re-employment.

We thank Richard Rance for assisting with questionnaire design and data collection and input, the NHS Pensions Agency for financial support and for allowing us access to its records, Medical and Industrial Services for its help in mailing the questionnaires and retrieving data from the application forms for retirement on grounds of ill health, and Professor Charles Normand and Mr Gary Cole for advice on cost calculations.

Contributors: SP, NC, and SW designed the study, devised the data collection instruments, and wrote the paper. SP and SW obtained the funding. SP oversaw data collection and obtained ethical approval. NC analysed the data. SW conceived the idea and oversaw the study. SP is guarantor of the study.

Funding: Part-funded by the NHS Pensions Agency.

Competing interests: None declared.

1 The NHS Pensions Agency annual report and accounts 1998-99. London: Stationery Office, 1999

2 Government Statistical Service. Health and personal social services statistics for England. London: Stationery Office, 1998.

3 Directly employed NHS nom-medical and dental staff in post at 30th September 1997. Cardiff: National Assembly for Wales Statistical Directorate, 1998.

4 Directly employed NHS medical staff in post at 30th September 1997. Cardiff: National Assembly for Wales Statistical Directorate, 1998.

5 Poole CJM. Retirement on grounds of ill-health: cross sectional survey in six organisations in United Kingdom. BMJ 1997;314:929-32.

(Accepted 11 September 2000.)

\section{A device that changed my practice Palmtop medical information}

Medical practice is increasingly being computerised. In our offices we use our PCs to prescribe electronically with fewer errors, automatic recognition of potential drug interactions and allergies, and more legible scripts. Clinical decision support software offers the potential to add rigour to our decision making. Many of us use real time web access to support this functionality. How can these important developments be extended to our work in the emergency department, on home visits, while caring for patients in institutions, and other settings where the practitioner is away from the office and its resources?

It is possible, although impractical, to take a laptop along and access the internet either via standard or mobile telephone. However, use of a hand-held computing device offers a much more palatable solution. There are many devices on the market. For months now I have used a Palm Pilot Vx (www.palm.com) weighing just over $100 \mathrm{~g}$ and fitting into my shirt pocket as diary, address book, and notepad, and it synchronises with my office PC easily through a cradle or infrared port. Recently I have also started using it in my medical practice.

Firstly, I installed a comprehensive clinical drug information guide that I now regularly use to check my prescribing when out of the office (www.epocrates.com). The database is automatically updated daily through the web when I synchronise the Palm with my office PC. Thus, using the Palm to support my prescribing is quicker, more accurate, and much more accessible than any paper-based resource. My Palm now also has, among others, programs to calculate cardiovascular risk, intravenous drug doses, and gestational age (www.palmspot.com/software/Medical/). This weekend I found the Merck Manual (one of my favourite resources) available for free download in Palm format (www.handheldmed.com) and the entire manual now resides on my Palm.

I saw 56 patients while on duty at the local hospital yesterday. I used the Palm to check prescribing 10 times and to inform my therapeutic decision making six times. Access was simple, easy, quick, and unobtrusive to the clinical encounter.

I feel that I have entered a new era in my medical practice. For the first time I have evidence in easily accessible format at my fingertips wherever I am.

David Wilkinson professor of rural health, Adelaide University and University of South Australia

We welcome articles of up to 600 words on topics such as A memorable patient, A paper that changed my practice, My most unfortunate mistake, or any other piece conveying instruction, pathos, or humour. If possible the article should be supplied on a disk. Permission is needed from the patient or a relative if an identifiable patient is referred to. We also welcome contributions for "Endpieces," consisting of quotations of up to 80 words (but most are considerably shorter) from any source, ancient or modern, which have appealed to the reader. 